\title{
Local anthropogenic contamination affects the fecundity and reproductive success of an Arctic amphipod
}

\author{
Lis Bach $^{1,2, *}$, Astrid Fischer ${ }^{1,3}$, Jakob Strand $^{1}$ \\ ${ }^{1}$ Department of Marine Ecology, National Environmental Research Institute, Aarhus University, Denmark \\ ${ }^{2}$ Department of Environmental, Social and Spatial Change, Roskilde University, Denmark \\ ${ }^{3}$ Department of Toxicology, Wageningen University and Research Centrum, Wageningen, The Netherlands
}

\begin{abstract}
This study investigates whether adaptation to life in contaminated Arctic areas carries a cost for the populations in terms of reduced fecundity and reproductive success. The benthic amphipod, Orchomenella pinguis occurs in huge densities in both clean and contaminated sites. O. pinguis was collected at contaminated sites in an open fjord adjacent to Sisimiut, West Greenland, and at clean sites outside the fjord exposed to open waters. The broods of gravid females were analyzed for number of embryos, embryonic developmental stage and number of embryo abnormalities. Further, a sample from 3 of the sites was sexed and analyzed for intersex occurrence. The individuals collected at the most contaminated site had significantly higher fecundity (i.e. reproductive potential), but also higher frequency of embryo aberrations resulting in lower fertility (i.e. actual reproductive success) compared to clean site individuals. These results indicated a cost of living in highly contaminated environments in terms of reduced reproductive success. This study confirms the potential of the benthic amphipod $O$. pinguis as a bioindicator for assessments of reproductive effects of contaminants in the Arctic marine environment.
\end{abstract}

KEY WORDS: Orchomenella pinguis $\cdot$ Embryo development $\cdot$ Embryo aberrations $\cdot$ Greenland

\section{INTRODUCTION}

The effects of pollution on wildlife and other organisms in the Arctic marine environment are of great concern, as many pollutants can have long-term impacts on reproduction, embryo development, growth or in other ways pose a risk to the health of animal populations (Attrill \& Depledge 1997, Matthiessen \& Law 2002, Wu et al. 2005). Despite this concern, there are very few toxicity studies for polar marine species, vertebrate or invertebrate (Chapman \& Riddle 2005). Benthic amphipods have potential as sensitive bioindicator organisms of contaminant-induced effects in marine ecosystems (Thomas 1993), and are also widespread in Arctic environments.

The economy of Greenland, like most Arctic areas, is highly dependent on marine ecosystem services since a large part of the human population hunts and fishes locally. Given that most of Greenland's exports are also based on fisheries, the maintenance of both local food supply and the economy is highly reliant on the protection of the marine local habitats. However, the longrange transport of contaminants (Lockhart 1995, Riget et al. 2004), together with structural changes in Greenland leading to more centralized consumer and industrial activities, have resulted in a larger and more geographically concentrated discharge of contaminants into the marine ecosystem.

One method to assess effects of contamination is through the use of bioindicator organisms, which are any kind of species whose function, status or population productivity can be used to determine the state of the ecosystem they inhabit (Adams 2005). For the West Greenland marine ecosystem we suggest the benthic 
amphipod Orchomenella pinguis (Lysianassidae) as a useful bioindicator species, since it is a highly common macroinvertebrate in the area (Bach et al. 2009). Further, O. pinguis is, like other lysianassid species, important in the benthic food chain where it forms an essential link by decomposing organic matter and as a food item for vertebrate predators such as fish and birds (De Lange et al. 2005, Ide et al. 2005). In addition, this species is relatively stationary, present in huge densities, easy to sample and has a circumpolar distribution (Horner \& Murphy 1985, Sainte-Marie 1986a,b, 1991, Legezynska et al. 2000, Bach et al. 2009).

Contaminants can have a wide range of effects on marine organisms. Several studies have reported impacts of contaminants on reproductive success in amphipod populations, including embryo aberrations (Sundelin \& Eriksson 1998, Camus \& Olsen 2008, Sundelin et al. 2008b, Pastorinho et al. 2009) and reduced fertility resulting from the occurrence of intersex (Ford et al. 2003a,b, Ford \& Fernandes 2005). Amphipods are model organisms for reproductive studies. They are easy to examine as there is no pelagic larval phase and embryos are carried maternally in a ventral brood pouch (marsupium) from fertilization of the eggs to their emergence as fully developed juveniles. Amphipods have thus been recommended as useful bioindicator species to assess effects of contaminants on invertebrate reproduction (Sundelin et al. 2008a).

The fjord Ulkebugten (Sisimiut, West Greenland) is impacted by untreated wastewater from different sources including households (approximately 5500 inhabitants), a hospital, a fish factory, and other industries, as well as a great deal of boat, trawler and cruise traffic. This has resulted in a fjord contaminated with e.g. polycyclic aromatic hydrocarbons (PAHs) and heavy metals (Bach et al. 2009; summarized in Table 1). However, at all sites (including inside the harbor and at the hospital wastewater outlet) where sampling was attempted, Orchomenella pinguis occurred in large densities despite high contamination levels, indicating that this species has high capacity to adapt to live in contaminated environments. As a study area, this fjord was ideal because of the availability of sites with different contamination inputs in close vicinity (max. $5 \mathrm{~km}$ ) to clean sites.

This study is based on previous findings of dense occurrences of $O$. pinguis at both clean and highly contaminated sites (Bach et al. 2009). The overall objective of this study was to investigate if adaptation to life in contaminated areas carries a cost in terms of reduced fecundity (i.e. reproductive potential) and impaired fertility (i.e. actual reproductive success) for populations of the Arctic benthic dwelling amphipod, Orchomenella pinguis, in the fjord Ulkebugten, Sisimiut, Greenland.

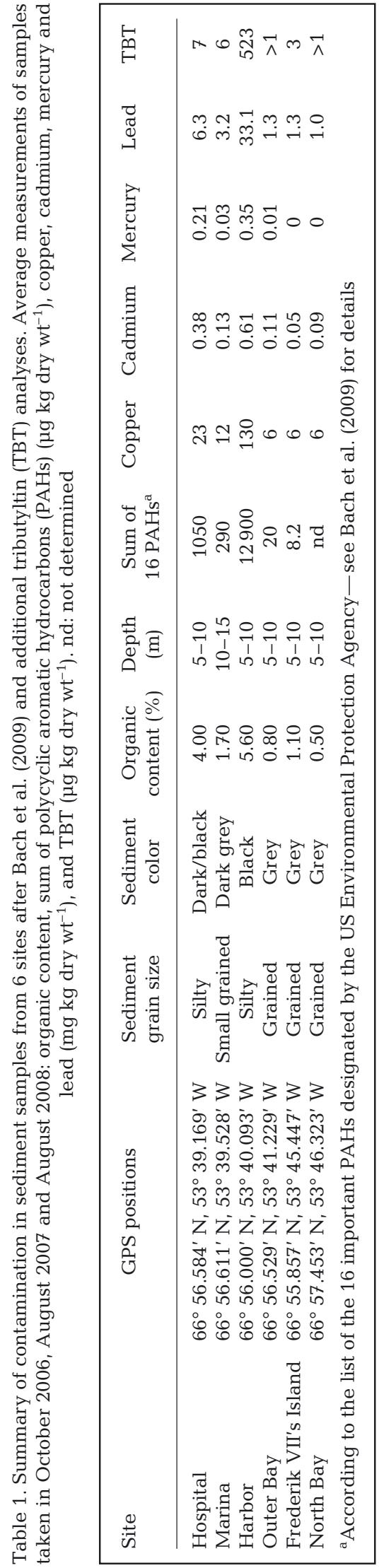




\section{MATERIALS AND METHODS}

Study area. Orchomenella pinguis was sampled in August 2008 in Ulkebugten, an open fjord in Sisimiut on the western coast of Greenland. Six sampling sites (Fig. 1) were selected based on knowledge of local contamination sources and levels (summarized in Table 1) from a previous study (Bach et al. 2009) and additional data for tributyltin (TBT) analyzed as described by Strand et al. (2006). Three sites (sites 1 to 3 ) are located within the fjord, close to point sources: (1) the Hospital outlet, (2) the Marina and (3) inside the Harbor. One site, (4) Outer Bay, is located facing the open waters, outside town but close to the small airport. The 2 reference sites (5) Frederik VII's Island and (6) North Bay were located outside the fjord and exposed to the open water masses. All sites were within a distance of $\sim 5 \mathrm{~km}$ from each other and equally influenced by tides, temperature $\left(\sim 6^{\circ} \mathrm{C}\right)$ and a stable salinity $(\sim 33)$.

Sampling and analyses. Amphipods were sampled overnight using traps baited with fish tissue. In most cases, this sampling method provided more than a thousand individuals in each catch. The amphipods were kept in large buckets (10 l) in cold, aerated seawater and supplied with sediment and algae (Ulvae sp.) as natural substrates and cover until processing. Shortly after sampling, a number of brood bearing females from each site was sorted from the overall sample consisting of juveniles, males and mature females. Gravid females were easily recognized because they appear more stocky than males and nongravid females and because eggs and embryos in the marsupium showed through the coxal plates as a red/purple mass. A picture was taken of the gravid females using a dissection microscope with a camera attached for later measurements of individual body length (anterior end of the cephalon to the distal end of

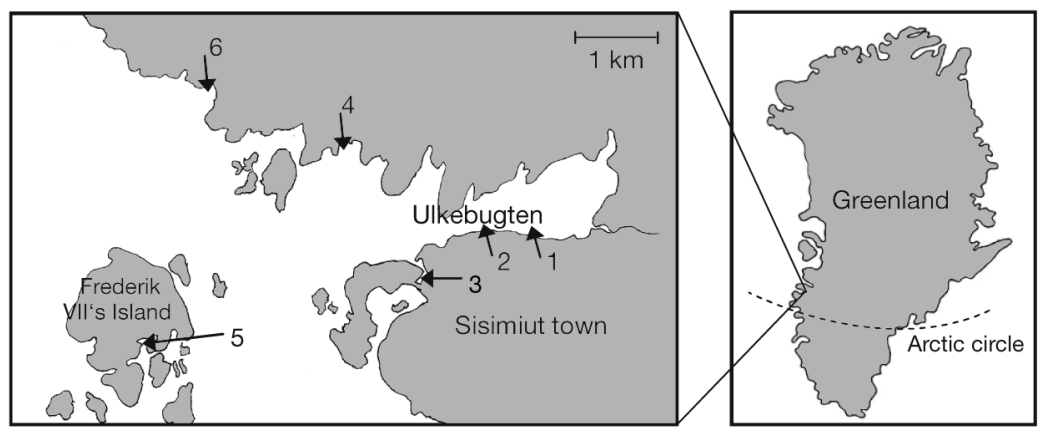

Fig. 1. Sampling sites in Sisimiut, Greenland, 2008. Locations range from the inner part of the fjord Ulkebugten to open waters. Three sites are close to point sources of contamination: (1) Hospital outlet, (2) Marina, and (3) the Harbor. One site: (4) Outer Bay, faces open water but is close to the small airport. Two reference sites are exposed to open water masses: (5) Frederik VII's Island and (6) North Bay the telson) using an image analysis program (SigmaScan Pro version 5.0.0). Eggs and embryos were gently removed from the living females and the number, developmental stage and frequency of embryo aberrations per brood per female were scored for each female. Embryonic stages were categorized as shown in Fig. 2, after Sundelin \& Eriksson (1998), with species-specific modifications.

The aberrations found in embryos in this study (Fig. 3) included twin eggs, undifferentiated eggs and embryos with ceased development, oedema and impaired membranes, and other non-specific aberrations; they were similar to those described by Sundelin et al. (2008a) and found by Camus \& Olsen (2008). A high frequency of pale embryos was found in the broods of Harbor females, which themselves were somewhat paler than females from other sites. A smallscale study based on ex vivo cultivation of pale embryos from the Harbor, resulted in high frequency of later-occurring aberrations, total arrest in embryonic stages or delayed development; all with less output of vital juveniles compared to a parallel study with embryos from the North Bay where a $100 \%$ normal output was found. As a result of these findings the pale embryos were categorized as aberrations.

The term 'embryo' is used synonymously with egg throughout the manuscript and thus also includes early-stage unfertilized eggs. Based on previous hatching experiments, embryos were also classified abnormal if the developmental stage was $\geq 2$ stages delayed compared to the rest of the embryos in the brood. For analysis of results, all types of aberrations were categorized as one group. To distinguish between severity of embryo aberrations per female, the percentage was calculated and indexed into $>2-5 \%,>5-20 \%,>20-$ $50 \%$ and $>50-100 \%$ embryo aberrations per female. Differences between sites for female size and brood size were tested by the non-parametric Kruskal-Wallis test, since assumptions of normality and homogeneity of variances could not be met. Site differences in the frequencies of broods with embryo aberrations were tested with $2 \times 2$ contingency tables and followed by a $\chi^{2}$ test.

The intersex analysis was restricted to 3 sites: Hospital, Harbor and North Bay. After removal of gravid females, subsamples of the samples from these sites were prepared. From each sub-sample, a number of individuals $(34,44$ and 42 , respectively) was sorted under a stereo microscope and divided into males, mature females, immature females (i.e. with rudimentary brood plates) and juveniles. Gender and intersex occurrence were 

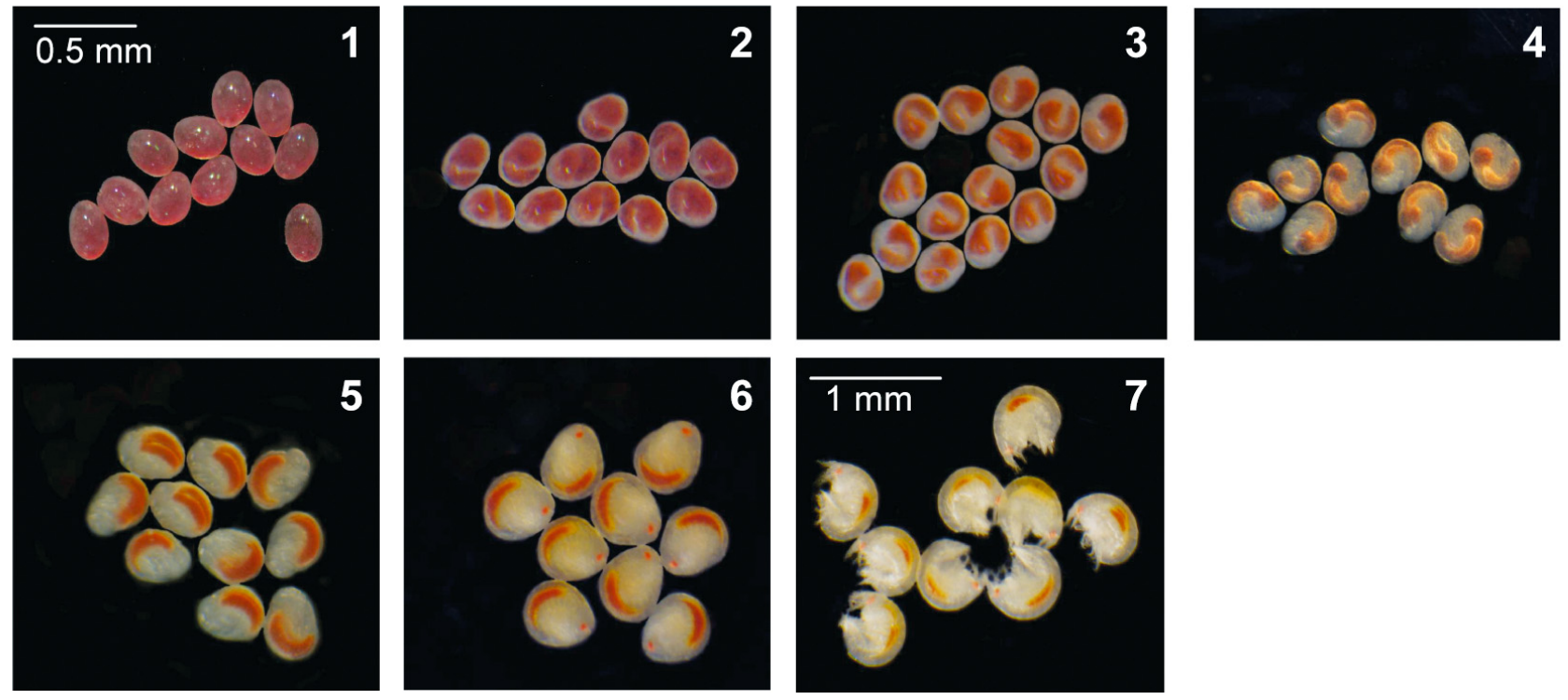

Fig. 2. Orchomenella pinguis. Characterization of embryonic development of $O$. pinguis. Seven embryonic stages of embryogenesis were adapted: (1) oval blastocytes, red eggs in early cleavage stages, but with no clear structure; (2) small fracture, formation of the caudal furrow; (3) widening of the caudal furrow and appearance of appendages rudiments; (4) dorsal organ is formed and the embryo is characterized by a comma shape and segmentation of appendages; (5) appendages and eye pigments become visible and the embryo is shaped like a half moon; (6) dorsal organ has decreased and the embryos have clearly developed red eyes;

(7) hatched juveniles inside brood chamber, potentially free swimming
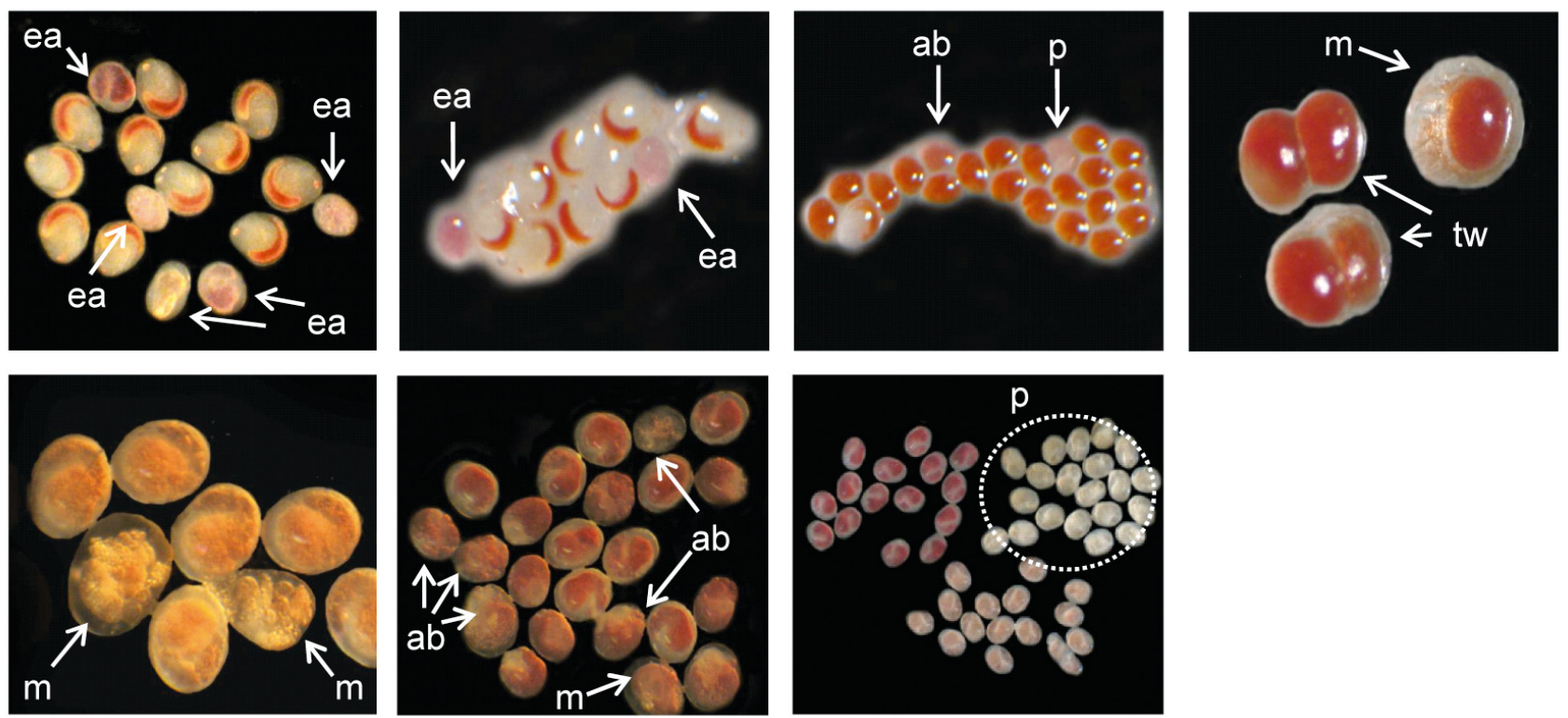

Fig. 3. Orchomenella pinguis. Pictures of embryo aberrations (indicated by arrows) show examples of undifferentiated eggs and embryo arrests, twin eggs and differentiated embryo pigmentation. Aberration types are ab: undefined aberrations; ea: embryo arrest (dead); m: membrane impaired; p: pale (dead) and tw: twin eggs

analyzed after Ford et al. (2003b), where intersex was classified as presence of rudimentary brood plates and 1 or 2 genital papillae. Site differences in the gender and intersex occurrence were tested with $2 \times 4$ contingency tables and followed by a $\chi^{2}$ test.

\section{RESULTS}

The embryonic stages for Orchomenella pinguis were comparable to those described by Sundelin \& Eriksson (1998) and used by Camus \& Olsen (2008) on 
individuals of Monoporeia affinis and Gammerus wilkitzkii, respectively. However, for O. pinguis the embryonic development was categorized into only 7 stages as the blastocytes in the early cleavage stages were grouped into one (Fig. 2).

\section{Brood size}

Females carrying broods were in the sizes of 6.4 to $13.4 \mathrm{~mm}$ and the average number of embryos per female was $20 \pm 10\left( \pm \mathrm{SD}_{\text {; }}\right.$ range: 3 to 44$)$. As the females from the Harbor were significantly larger (Kruskall-Wallis: $\mathrm{p}<0.05$ ) than from any of the other sites, and as a relation between size and number of offspring previously has been described for other amphipods (Nelson 1980, Ford et al. 2003a), data were normalized by division by female length $(\mathrm{mm})$. A comparison of the mean brood size per female (normalized to female length) for each site (Table 2) shows that despite the normalization the Harbor females still carried significantly larger broods than females at any of the other sites (Kruskall-Wallis: $\mathrm{p}<0.01$ ), with females at Outer Bay and the reference sites (Frederik VII's Island and North Bay) carrying the smallest broods. Brood size in the Harbor was also larger when specified to each embryonic stage. Further, slightly more embryos occurred in the early stages 1 to 2 than in the later stages 5 to 7 at most sites.

\section{Embryo aberrations}

The percentage of females carrying broods with aberrations (Fig. 4$)$ was significantly higher $(2 \times 2$ contingency table: $\mathrm{p}<0.01)$ in the Harbor $(49 \%)$ compared to all other sites, i.e. Marina (11\%), Hospital $(12 \%)$, Outer Bay $(0 \%)$ and the 2 reference sites Frederik VII's Island $(0 \%)$ and North Bay $(16 \%)$.

The Harbor site was furthermore the only site with females carrying broods with more than $20 \%$ abnormal embryos (Fig. 4). The highest occurrence of aberrations in Harbor embryos was found in broods at the later embryonic stages 4 to 6 , where the average frequency of embryo aberrations per brood reached 25 to $43 \%$ (Fig. 5).

\section{Intersex}

Among the studied specimens, no observations of female or male intersex at any of the sites were made (Fig. 6). There were however small differences, though none statistically significant, in the frequency of immature females between clean and contaminated sites.

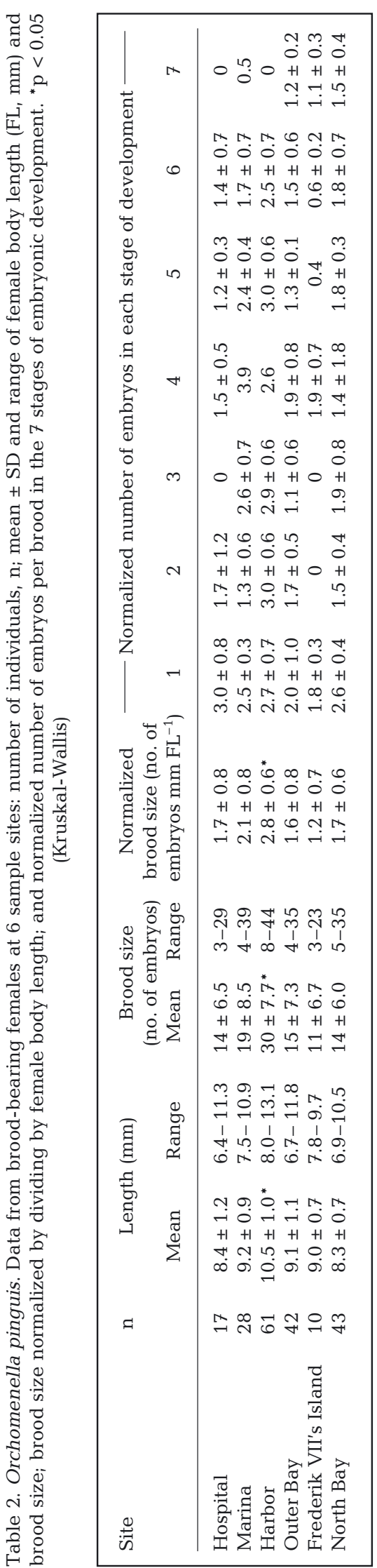




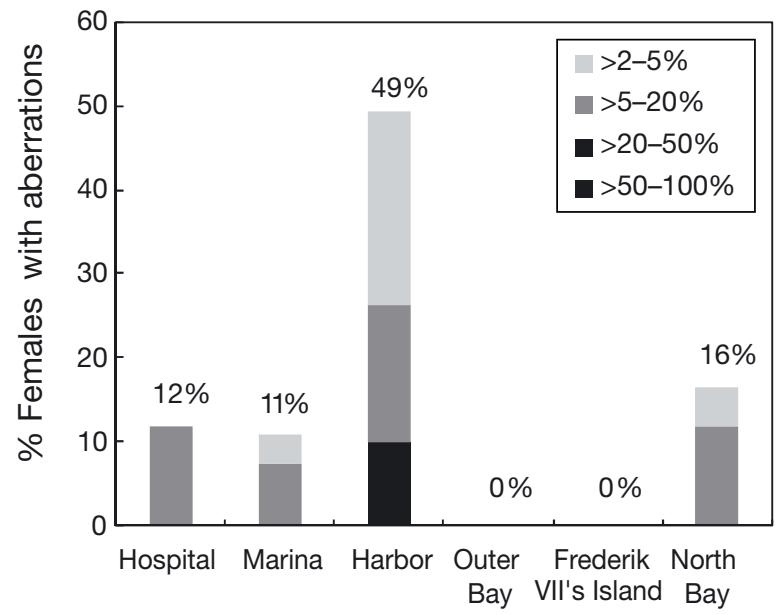

Fig. 4. Orchomenella pinguis. Percentage of females within each site carrying broods with aberrations (see Fig. 3). The degree of aberrations is indexed within each brood into $>2-5 \%$, > $5-20 \%$, > $20-50 \%$ and $>50-100 \%$ embryo aberrations per female

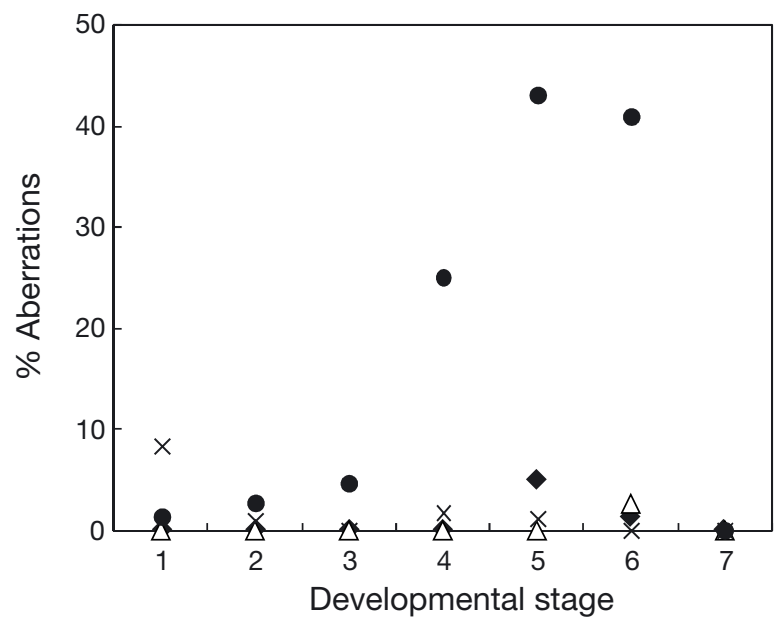

Fig. 5. Orchomenella pinguis. Percentage embryo aberrations at each developmental stage for the $(\diamond)$ Hospital, $(\Delta)$ Marina, (๑) Harbor and $(\times)$ North Bay. See Fig. 2 for developmental stages

Adding the 2 female groups: mature and immature females, but excluding the undifferentiated group (and the already sorted gravid females), more females than males were found at the Hospital and Harbor (63:37 and 61:31, respectively) while the gender distribution was equal (50:50) in North Bay.

\section{DISCUSSION}

The reproductive patterns of Orchomenella pinguis were studied at contaminated and clean sites. Brood size, embryonic developmental stages and number of

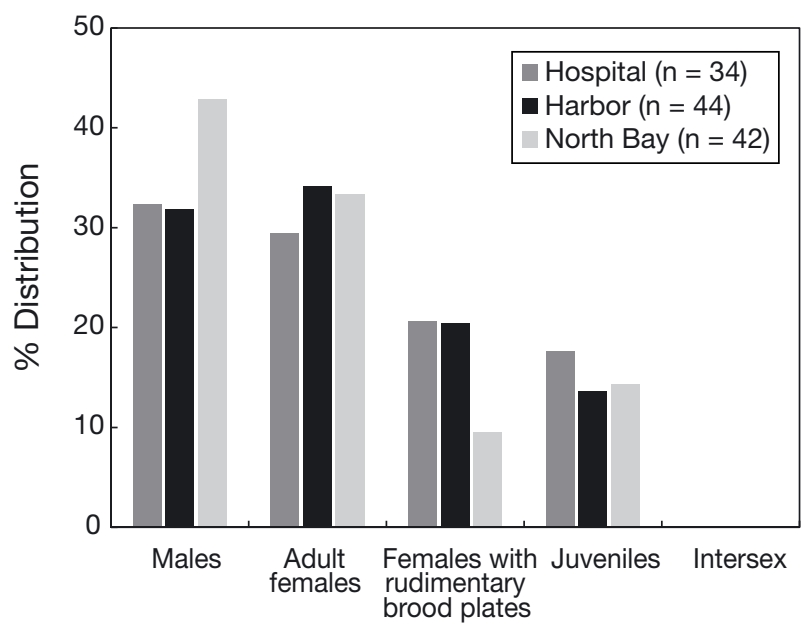

Fig. 6. Orchomenella pinguis. Gender and intersex distribution for the Harbor, Hospital and North Bay samples

eggs over embryo aberrations as well as gender and incidences of intersex were recorded. All parameters used can be negatively affected by contamination and may carry costs in terms of reduced fertility as result of e.g. smaller brood sizes, lower embryo survival, delayed maturation and reduced pairing success (Sundelin \& Eriksson 1998, Ford \& Fernandes 2005).

A small fraction of the sampled individuals was gravid females. Occasionally the gravid females were found with full ovaries with unfertilized oocytes as well, confirming that Orchomenella pinguis is iteroparous as suggested by Sainte-Marie (1990). While the size of the gravid females corresponded to the size of gravid females collected in Saint Lawrence Estuary (Sainte-Marie 1990), the broods were found to be much smaller in the present study. This may reflect differences in food availability or a combination of geographical life history differences. Even within the present study, differences in body and brood size were found for different sites. At the most contaminated site, the Harbor, amphipod females were larger than the females collected at the other sites, and even after normalizing to length these females still carried larger broods. Whether this is an effect of larger body size, higher food availability or is an attempt to overcome the higher degree of aberrations found in broods at this site can only be speculated. However, the finding contradicts the 'cost of stress hypothesis' by Calow \& Sibly (1990), whereby smaller broods are hypothesized to occur in stressed individuals due to reallocation of energy from growth and reproduction towards stress defenses. Another factor which can affect the brood size of amphipods is a potential loss of embryos from the brood either resulting from active rejection of dead/malformed embryos or due to abnormal brood 
plate development (Ford et al. 2003a). This might be the reason for the slightly smaller brood sizes observed in the later embryonic stages 4 to 6 at most of the sites in Ulkebugten.

The findings of high levels of embryo aberrations in the broods of Harbor females, and to a lesser degree in Hospital, Marina and North Bay females, indicate pollution effects, and are as such in agreement with the studies by Sundelin \& Ericsson (1998) and Camus \& Olsen (2008). Both found severe damage in embryos of amphipods collected near an aluminum smelter with high PAH concentrations and in embryos exposed to PAHs under laboratory conditions, respectively. While contaminants in general can cause malformed embryos, exposure to hypoxia may result in dead eggs and embryos (Sundelin et al. 2008a, and references herein). Particularly high levels of PAHs have been reported from the Harbor in Ulkebugten (Bach et al. 2009; Table 1) and these may, alone or in conjunction with other contaminants such as TBT, have triggered the high frequency of embryo aberrations in Harbor broods in the present study. TBT was also found in high concentrations in the Harbor sediments and though no studies, to our knowledge, have addressed the direct effects of TBT on amphipod embryo development, reproductive effects of TBT have been found in e.g. fish larvae (Fent \& Meier 1992, Bodammer 1993).

Though the evidence for embryo aberrations was only really strong at the Harbor site (49\%), there were also lower frequencies of broods with aberrations at the Hospital (12\%), Marina (11\%) and North Bay $(16 \%)$, which are higher than the assumed background levels of $5 \%$ in amphipods (Sundelin et al. 2008a). The findings for the Hospital and Marina correspond to the contamination levels at these sites, which are elevated but lower than in the Harbor. The occurrence of broods with embryo aberrations at the reference site North Bay cannot be explained by the measured contamination levels, but may be attributed to other contaminants.

Regarding intersex, other studies report observations of intersex in amphipods from contaminated sites related to direct contamination effects, incomplete feminization by microsporidian parasites, or as a consequence of environmental sex determination (Ford et al. 2003b, Ford \& Fernandes 2005). In the present study, there were no indications of development of intersex in Orchomenella pinguis in individuals from the 3 sites studied. Females with rudimentary brood plates are suggested by Ford et al. (2003b) to represent a form of endocrine dysfunction, similar to that of intersex, as they are often observed in populations with high incidence of intersex. Whether the finding of the higher frequency of females with rudimentary brood plates in both Hospital and Harbor compared to the clean site (North Bay) is due to natural differences in amphipod maturation processes and/or to contamination effects as suggested by Ford et al. (2003b) and thus in the category of intersex, is unclear at present.

The impact of contaminants on the amphipods and in particular on their fecundity may not only affect individuals but the overall population size and productivity over the long-term. As amphipods are brooders and carry their young in a brood pouch until they hatch as fully developed juveniles, contaminants affecting adults will also affect their offspring as they are released into the same environment. This can be expected to have consequences in terms of slower recruitment and/or re-colonization. The Harbor population may already have experienced such population-level effects. The sampling in August 2008 and an additional sampling in 2009 yielded much fewer individuals at the Harbor site that at earlier samplings in August 2006 and August 2007 (Bach et al. 2009); this is indicative of recent environmental changes, and severe pollution events like oil spills cannot be excluded.

These results indicate a cost of living in highly contaminated environments in terms of reduced reproductive success, shown by an increase in embryo aberrations, possibly accompanied by the development of different reproductive strategies to overcome that cost. For future studies of the costs of living in contaminated areas in terms of reproduction, other parameters such as time to reproduction onset, embryo development time and juvenile growth and survival are suggested to be included. Further field and laboratory studies are also needed to evaluate if the reproductive changes in the amphipods can be mainly attributed to contaminants or if other environmental stressors also have significant effects.

\section{CONCLUSION}

The Orchomenella pinguis sample collected at the most contaminated site in the Harbor, had higher frequency of broods with embryo aberrations compared to samples from cleaner reference sites and also from less contaminated sites. However, the Harbor females also produced larger broods; but whether this has evolved as a reproductive strategy to overcome the greater embryonic loss or is an effect of higher food accessibility remains unclear. A larger suite of environmental stressors should be included in future studies to enable separation of environmental influences from the effects of contaminants.

Acknowledgement. We thank A. Willumsen and staff at Department of Arctic Technology, Technical University of Denmark, and Sanaartornemik Illiniarfik for providing research facilities in Sisimiut, Greenland. 


\section{LITERATURE CITED}

Adams SM (2005) Assessing cause and effect of multiple stressors on marine systems. Mar Pollut Bull 51:649-657

Attrill M, Depledge MH (1997) Community and population indicators of ecosystem health: targeting links between levels of biological organisation. Aquat Toxicol 38: 183-197

Bach L, Forbes VE, Dahllöf I (2009) The amphipod Orchomenella pinguis - a potential bioindicator for contamination in the Arctic. Mar Pollut Bull 58:1664-1670

Bodammer JE (1993) The teratological and pathological effects of contaminants on embryonic and larvae fishes exposed as embryos: a brief review. Am Fish Soc Symp 14: $77-84$

Calow P, Sibly RM (1990) A physiological basis of population processes: ecotoxicological implications. Funct Ecol 4: $283-288$

Camus L, Olsen GH (2008) Embryo aberrations in sea ice amphipod Gammarus wilkitzkii exposed to water soluble fraction of oil. Mar Environ Res 66:221-222

Chapman PM, Riddle MJ (2005) Toxic effects of contaminants in polar marine environments. Environ Sci Technol 39: 200A-207A

> De Lange HJ, De Haas EM, Maas H, Peeters E (2005) Contaminated sediments and bioassay responses of three macroinvertebrates, the midge larva Chironomus riparius, the water louse Asellus aquaticus and the mayfly nymph Ephoron virgo. Chemosphere 61:1700-1709

Fent K, Meier W (1992) Tributyltin-induced effects on early life stages of minnows Phoxinus phoxinus. Arch Environ Contam Toxicol 22:428-438

Ford AT, Fernandes TF (2005) Notes on the occurrence of intersex in amphipods. Hydrobiologia 548:313-318

Ford AT, Fernandes TF, Rider SA, Read PA, Robinson CD, Davies IM (2003a) Measuring sublethal impacts of pollution on reproductive output of marine Crustacea. Mar Ecol Prog Ser 265:303-309

Ford AT, Fernandes TF, Rider SA, Read PA, Robinson CD, Davies IM (2003b) Reproduction in the amphipod, Echinogammarus marinus: a comparison between normal and intersex specimens. J Mar Biol Assoc UK 83:937-940

Horner R, Murphy D (1985) Species composition and abundance of zooplancton in the nearshore Beaufort Sea in winter-spring. Arctic 38:201-209

Ide K, Sasaki K, Omori M (2005) Food intake and digestion in the scavenging lysianassid gammaridean Scopelocheirus onagawae. Fish Sci 71:721-730

Legezynska J, Weslawski JM, Presler P (2000) Benthic scavengers collected by baited traps in the high Arctic. Polar Biol 23:539-544

Editorial responsibility: Hans Heinrich Janssen, Oldendorf/Luhe, Germany
Lockhart WL (1995) Implications of chemical contaminants for aquatic animals in the Canadian Arctic: some review comments. Sci Total Environ 160-161:631-641

> Matthiessen P, Law R (2002) Contaminants and their effects on estuarine and coastal organisms in the United Kingdom in the late twentieth century. Environ Pollut 120: 739-757

Nelson WG (1980) Reproductive patterns of gammeridean amphipods. Sarsia 65:61-71

Pastorinho MR, Telfer TC, Soares AMVM (2009) Amphipod intersex, metals and latitude: a perspective. Mar Pollut Bull 58:812-817

Riget F, Law RJ, Hansen JC (2004) The state of contaminants in the Greenland environment. Sci Total Environ 331:1-4

Sainte-Marie B (1986a) Effect of bait size and sampling time on the attraction of the lysianassid amphipods Anonyx sarsi (Steele \& Brunel) and Orchomenella pinguis (Boeck). J Exp Mar Biol Ecol 99:63-77

> Sainte-Marie B (1986b) Feeding and swimming of lysianassid amphipods in a shallow cold-water bay. Mar Biol 91: $219-229$

> Sainte-Marie B (1990) Reproductive bionomics of some shallow-water lysianassoids in the Saint Lawrence Estuary, with a review on the fecundity of the Lysianassoidea (Crustacea, Amphipoda). Can J Zool 68:1639-1644

Sainte-Marie B (1991) A review of the reproductive bionomics of aquatic gammaridean amphipods: variation of life history traits with latitude, depth, salinity and superfamily. Hydrobiologia 223:189-227

- Strand J, Glahder CM, Asmund G (2006) Imposex occurrence in marine whelks at a military facility in the high Arctic. Environ Pollut 142:98-102

Sundelin B, Eriksson AK (1998) Malformations in embryos of the deposit-feeding amphipod Monoporeia affinis in the Baltic Sea. Mar Ecol Prog Ser 171:165-180

Sundelin B, Eriksson Wiklund AK, Ford AT (2008a) Biological effects of contaminants: the use of embryo aberrations in amphipod crustaceans for measuring effects of environmental stressors. ICES Tech Mar Environ Sci 41

Sundelin B, Ford A, Jacobson T (2008b) Using embryo and reproductive abnormalities in amphipods to assess the impact of an ironwork. Mar Environ Res 66:53

Thomas JD (1993) Biological monitoring and tropical biodiversity in marine environments:a critique with recommendations, and comments on the use of amphipods as bioindicators. J Nat Hist 27:795-806

Wu RSS, Siu WHL, Shin PKS (2005) Induction, adaptation and recovery of biological responses: implications for environmental monitoring. Mar Pollut Bull 51:623-634

Submitted: September 16, 2009; Accepted: October 11, 2010 Proofs received from author(s): November 28, 2010 